\title{
Clinical psychology of Internet addiction: a review of its conceptualization, prevalence, neuronal processes, and implications for treatment
}

This article was published in the following Dove Press journal:

Neuroscience and Neuroeconomics

28 May 2015

Number of times this article has been viewed

\section{Halley M Pontes \\ Daria J Kuss \\ Mark D Griffiths}

International Gaming Research Unit, Psychology Division, Nottingham

Trent University, Nottingham, UK
Correspondence: Halley M Pontes Graduate School, Nottingham Trent University, Burton Street,

Nottingham NGI 4BU, UK

Tel +44 0II5 94I 84I8

Email halley.pontes2013@my.ntu.ac.uk

\begin{abstract}
Research into Internet addiction (IA) has grown rapidly over the last decade. The topic has generated a great deal of debate, particularly in relation to how IA can be defined conceptually as well as the many methodological limitations. The present review aims to further elaborate and clarify issues that are relevant to IA research in a number of areas including: definition and characterization, incidence and prevalence rates, associated neuronal processes, and implications for treatment, prevention, and patient-specific considerations. It is concluded that there is no consensual definition for IA. Prevalence rates among nationally representative samples across several countries vary greatly (from $1 \%$ to $18.7 \%$ ), most likely reflecting the lack of methodological consistency and conceptual rigor of the studies. The overlaps between IA and other more traditional substance-based addictions and the possible neural substrates implicated in IA are also highlighted. In terms of treatment and prevention, both psychological and pharmacological treatments are examined in light of existing evidence alongside particular aspects inherent to the patient perspective. Based on the evidence analyzed, it is concluded that IA may pose a serious health hazard to a minority of people.
\end{abstract}

Keywords: Internet addiction, review, behavioral addictions, prevalence, neuronal processes, treatment

\section{Introduction}

Given the ubiquity of the Internet, its evolving nature as a modern tool of society, and issues surrounding its excessive use and abuse by a minority of people, Internet addiction (IA) has become an increasingly important topic for dedicated research agendas from several scientific fields including psychology, psychiatry, and neuroscience. Moreover, the number of users of the Internet is ever increasing. ${ }^{1}$ The latest International Telecommunication Union report predicted that by the end of 2014, around 44\% of the world's households will have Internet access, an increase of approximately $40 \%$ in comparison with $2013 .{ }^{2}$ Furthermore, it is generally agreed amongst scholars that the phenomenon of IA was initially reported and described in the psychological literature by both Young ${ }^{3,4}$ and Griffiths ${ }^{5,6}$ in the mid-1990s and that technological addictions were under scientific debate and scrutiny since this time, particularly in relation to addictions on the Internet as opposed to addictions to the Internet. ${ }^{7,8}$

Psychological phenomena of any kind, whether addictive or not, usually encompass various complex mechanisms and behavioral properties that are better understood from a biological, psychological, and/or sociological point of view, making it difficult to provide standalone definitions for such phenomena. Likewise, the very concept of addiction does not have a unique all-encompassing and widely accepted definition, ${ }^{9}$ 
let alone as applied to the concept of IA. Despite the controversies, IA has been referred to across the psychological, psychiatric, and neuroscientific literature by the adoption of different terms and nomenclatures such as Internet addiction disorder, ${ }^{4,10}$ pathological Internet use, ${ }^{11}$ compulsive Internet use, ${ }^{12}$ virtual addiction, ${ }^{13}$ and compulsive computer use, ${ }^{14}$ among others. For the purpose of the present review, the term Internet addiction is used for the sake of parsimony and consistency.

Given the extant debates in the field as to whether IA can stand on its own as a diagnosis (ie, as a primary disorder) or whether it is a consequence of other existing underlying mental disorders (eg, depression, anxiety, attention deficit hyperactivity disorder, other impulse control disorders, making it a secondary disorder), ${ }^{15,16}$ the purpose of this review is to highlight the issue of IA in terms of: definition and characterization; incidence and prevalence rates from robust studies (ie, those with nationally representative samples); its associated neuronal processes; and implications for treatment and prevention, along with patient-specific relevant considerations.

It is envisaged by the present authors that by clarifying such specific aspects based on the latest empirical findings and advancements in the field, a better understanding may be obtained for this emerging phenomenon that continues to generate a great deal of debate. ${ }^{17}$ Moreover, by reviewing the most recent empirical evidence, the present authors argue that IA can be a serious disorder affecting a minority of people, and can be understood and conceptualized within a behavioral addictions framework despite the methodological and conceptual limitations usually associated with this phenomenon.

\section{A critical approach to definition and characterization}

Generally speaking, IA has been characterized by excessive or poorly controlled preoccupation, urges, and/or behaviors regarding Internet use that lead to impairment or distress in several life domains. ${ }^{18}$ However, according to Young, ${ }^{4}$ IA is a problematic behavior akin to pathological gambling that can be operationally defined as an impulse control disorder not involving the ingestion of psychoactive intoxicants. Following the conceptual framework developed by Young et $\mathrm{al}^{19}$ to understand IA, five specific types of distinct online addictive behaviors were identified: "cyber-sexual addiction", "cyber-relationship addiction", "net compulsions" (ie, obsessive online gambling, shopping, or trading); "information overload"; and "computer addiction" (ie, obsessive computer game playing). Furthermore, and using a similar rationale, Block $^{15}$ defined IA as a compulsive-impulsive spectrum disorder involving online and/or offline computer usage patterns featuring excessive use, withdrawal symptoms, tolerance, and negative repercussions.

However, as noted above, it has also been argued that the Internet may simply be the means or "place" where the most commonly reported addictive behaviors occur. In short, the Internet may be just a medium to fuel other addictions. ${ }^{8,20,21}$ Interestingly, new evidence pointing toward the need to make this distinction has been provided from studies in the online gaming field where robust empirical evidence has demonstrated that IA is not the same as other more specific addictive behaviors carried out online (ie, gaming addiction), ${ }^{22}$ further magnifying the meaningfulness to differentiate between what may be called "generalized" and "specific" forms of online addictive behaviors, and also between IA and gaming addiction as these behaviors are conceptually different. ${ }^{17,23}$

Additionally, the lack of formal diagnostic criteria to assess IA represents another methodological problem, since researchers are systematically adopting modified criteria for pathological gambling to investigate IA. ${ }^{24}$ Although IA may share some commonalities with other substance-based addictions, ${ }^{25-27}$ it is unclear to what extent such criteria are useful and suitable to evaluate IA. Notwithstanding the existing difficulties in understanding and comparing IA and pathological gambling, recent research provided useful insights on this topic. A recent study by Tonioni et $\mathrm{al}^{28}$ involving two clinical groups (ie, 31 IA patients and eleven pathological gamblers) and a control group (ie, 38 healthy individuals) that aimed to investigate whether IA patients presented different psychological symptoms, temperamental traits, coping strategies, and relational patterns in comparison with pathological gamblers, concluded that Internet addicts presented higher mental and behavioral disengagement associated with significant more interpersonal impairment. Moreover, temperamental patterns, coping strategies, and social impairments appeared to be different across both disorders. Nonetheless, the similarities between IA and pathological gambling were essentially in terms of psychopathological symptoms such as depression, anxiety, and global functioning. Although individuals with IA and pathological gambling appear to share similar psychological profiles, previous research found no overlap between these two populations, ${ }^{29}$ thus it can be concluded that both phenomena are separate disorders. ${ }^{30}$

Despite the fact that initial conceptualizations of IA helped advance the current knowledge and understanding of 
IA in different aspects and contexts, it has become evident that the field has greatly evolved since then in several ways. As a result of these ongoing changes, behavioral addictions have now recently received official recognition in the DSM-5 (Diagnostic and Statistical Manual of Mental Disorders, Fifth Edition). ${ }^{31}$ Moreover, IA can also be characterized as a form of technological addiction, ${ }^{5-7}$ which is operationally defined as a non-chemical (behavioral) addiction involving excessive human-machine interaction. ${ }^{7}$ In this theoretical framework, technological addictions such as IA represent a subset of behavioral addictions featuring six core components: salience, mood modification, tolerance, withdrawal, conflict, and relapse. ${ }^{32,33}$ The components model of addiction appears to be a more updated framework for understanding IA as a behavioral addiction, not only conceptually but also empirically. Moreover, this theoretical framework has recently received empirical support from several studies, ${ }^{34,35}$ further evidencing its suitability and applicability to the understanding of IA.

The cognitive-behavioral framework has also inspired several scholars regarding the definition, conceptualization, and treatment of IA. One of the most influential cognitivebehavioral approaches was developed by Davis. ${ }^{36}$ His model of pathological Internet use was the first to clearly differentiate between specific pathological Internet use (SPIU) and generalized pathological Internet use (GPIU). According to Davis, ${ }^{36}$ SPIU can be broadly defined as a type of IA where people are dependent on a specific function or application of the Internet, whereas GPIU relates to a more general, multidimensional overuse behavioral pattern of the Internet. In this model, maladaptive cognitions play an important role in the development and maintenance of pathological Internet use. In order to describe the nature of the cognitive theory of pathological Internet use, Davis ${ }^{36}$ introduced concepts such as distal and proximal contributory causes of pathological Internet use. On one hand, distal causes may include pre-existing psychopathology (eg, depression, social anxiety, substance dependence) and behavioral reinforcement (ie, provided by the Internet itself throughout the experience of new functions and situational cues that contribute to conditioned responses). On the other hand, proximal causes may involve maladaptive cognitions that are seen as a sufficient condition with the potential to lead to both GPIU and SPIU and also cause the set of symptoms associated with pathological Internet use.

Davis $^{36}$ argued that GPIU involves spending abnormal amounts of time on the Internet, either wasting time with no direct purpose and/or spending excessive amounts of time in online chat rooms. Thus, procrastination is also assumed to play an important role in both the development and maintenance of GPIU. In this model, symptoms of pathological Internet use primarily derive from maladaptive cognitions. These symptoms relate more to cognitive symptoms and, as such, may include obsessive thoughts about the Internet, diminished impulse control, inability to cease Internet use, as well as a generalized feeling that the Internet is the only place where individuals feel good about themselves. ${ }^{36}$ Other consequent symptoms may include thinking about the Internet while offline, anticipating future time online, decreasing interest in other activities or hobbies, and social isolation. ${ }^{36}$

Despite the efforts to operationalize the cognitivebehavioral theories of IA, ${ }^{37-39}$ these theories usually lack robust standardized psychometric tools that fully capture the complexity of IA and it has mostly been considered a more generalized phenomenon. Additionally, new theoretical approaches recently developed based on the cognitive-behavioral model of Davis, ${ }^{25}$ still lack robust operationalization and valid standardized tests to assess the suitability of such theories in the measurement of IA.

Notwithstanding such debates, addictive Internet use is considered to be a serious issue by those working in the field, albeit not yet officially recognized as a disorder, and has been described across the literature as being associated with a wide range of co-occurring psychiatric comorbidities alongside an array of dysfunctional behavioral patterns. ${ }^{1,40-43}$ Additionally, IA has been recently associated with low life satisfaction, ${ }^{44}$ low academic performance, ${ }^{44}$ less motivation to study, ${ }^{45}$ poorer physical health, ${ }^{46}$ social anxiety, ${ }^{47}$ attention deficit/hyperactivity disorder and depression, ${ }^{48}$ poorer emotional wellbeing and substance use, ${ }^{49}$ higher impulsivity, ${ }^{50}$ cognitive distortion, ${ }^{51}$ deficient self-regulation, ${ }^{52}$ poorer family environment, ${ }^{53}$ higher mental distress,${ }^{54}$ and loneliness, ${ }^{55}$ among other negative psychological, biological, and neuronal aspects.

In a recent systematic literature review conducted by $\mathrm{Li}$ et al, ${ }^{56}$ the authors reviewed a total of 42 empirical studies that assessed the family correlates of IA in adolescents and young adults. According to the authors, virtually all studies reported greater family dysfunction amongst IA families in comparison with non-IA families. More specifically, individuals with IA more often exhibited: greater global dissatisfaction with their families; less organized, cohesive, and adaptable families; greater interparental and parent-child conflict; and perceptions of their parents as more punitive, and less supportive, warm, and involved. Furthermore, families were significantly more likely to have divorced parents or to be from a single-parent family.

Another recent systematic literature review conducted by $\mathrm{Lam}^{57}$ examined the possible links between IA and 
sleep problems. After reviewing seven studies (that met strict inclusion criteria), it was concluded that on the whole, IA was associated with sleep problems that encompassed subjective insomnia, short sleep duration, and poor sleep quality. The findings also suggested that participants with insomnia were 1.5 times more likely to be addicted to the Internet in comparison with those without sleep problems. Despite the strong evidence found supporting the links between IA and sleep problems, the author noted that due to the cross-sectional nature of most studies reviewed, the generalizability of the findings was somewhat limited. ${ }^{57}$

As shown by the various existing conceptual approaches to IA and its characterization via key correlates, IA is a relatively recent phenomenon that clearly warrants further investigation, and empirical studies suggest that it needs to be taken seriously by psychologists, psychiatrists, and neuroscientists. Although uncertainties still remain regarding its diagnostic and clinical characterization, ${ }^{58}$ it is likely that these extant difficulties will eventually be tackled and the field will evolve to a point where IA may merit full recognition as a behavioral addiction from official medical bodies (eg, the American Psychiatric Association) similar to other more established behavioral addictions such as "gambling disorder" and "Internet gaming disorder". However, in order to achieve official status, researchers will have to adopt a more commonly agreed upon definition as to what IA is, and how it can be conceptualized and operationalized both qualitatively and quantitatively (as well as in clinically diagnostic terms).

\section{Distinguishing between Internet addiction and excessive Internet use}

Distinguishing between IA and excessive Internet use is crucial given the overlapping boundaries between the two behaviors. Furthermore, it is generally agreed that although IA implies excessive Internet use patterns, excessive usage in itself does not necessarily translate into addiction, and that the context of excessive Internet use is also important. ${ }^{59}$ The differences between excessive Internet use and IA have been under scientific scrutiny from both empirical and theoretical points of view. ${ }^{60-62}$ More recently, Lee et a ${ }^{60}$ conducted a small-scale study using a sample of 125 male Korean adolescents to investigate the differences between excessive (termed as Internet abuse in the original study), addicted, and non-addicted users by comparing their results using diagnostic interviews and participants' levels of psychiatric comorbidities and other behavioral aspects. Consequently, after grouping the participants using the Internet Addiction Test $^{63}$ scores and a psychiatric diagnosis, significant differ- ences in psychiatric comorbidities and behavioral aspects were found between excessive and addicted users. More specifically, comorbidity rates were significantly higher in the addicted group than in the excessive group. Moreover, sleep disorders, mood changes, and preoccupation were more prominent in the addicted group. Additionally, while excessive users may not present with all six core criteria of addiction (ie, salience, mood modification, tolerance, withdrawal, conflict, and relapse) $)^{33}$ and are likely to experience fewer problems related to their Internet use in comparison with addicted users, the latter are usually characterized by significant impairments in several life domains as they continue to use the Internet despite adverse consequences. ${ }^{64}$

From a theoretical point of view, Caplan ${ }^{61}$ argued that excessive Internet use comprises a quantity or degree of online activity that exceeds what a person thinks of as normal, usual, or planned, whereas IA involves difficulty with impulse control. Although a majority of individuals consider their amount of time spent online to be excessive, this excess is perhaps more related to their reliance on the Internet to carry on daily activities (ie, functional rather than dysfunctional use) than with their psychosocial wellbeing. In this case, many people may report that they use the Internet excessively; however, most of these people use the Internet to obtain positive rather than negative outcomes that are related to their working and/or social lives. Additionally, Caplan ${ }^{62}$ also found that IA was more related to negative outcomes than excessive Internet use.

Given that the quantity or amount of time spent online by itself does not necessarily indicate problematic behavior, ${ }^{59,61}$ it can be concluded that in order to distinguish between IA and excessive Internet use, empirical and clinical attention should be paid to the extent of problems Internet use may or may not cause for a user and how the Internet impacts on the user's life in terms of biological, social, and psychological wellbeing. The fact that it is often difficult for users to accurately differentiate the amount of time spent online for educational and/or work-related purposes from that for noneducational/non-work-related purposes may contribute to this inherent difficulty in distinguishing between both excessive and addictive Internet use from the users' perspective. ${ }^{65}$

\section{Internet addiction: prevalence estimates}

Investigating the incidence and prevalence rates of IA in the general population is paramount to assess the demand for consulting, treatments, and preventive measures. ${ }^{66}$ However, IA research that attempts to estimate the prevalence rates for IA is usually faced with several methodological shortcomings. 
On one hand, there are currently no consensual criteria for IA, which directly impacts on the adequacy, reliability, and validity of studies using inconsistent diagnostic instruments to assess this phenomenon. ${ }^{67}$ On the other hand, despite the difficulties concerning the diagnosis and heterogeneity of instruments to assess IA, most studies reporting prevalence rates for IA suffer from sampling selection biases due to systematic use of nonprobability sampling techniques (eg, convenience samples) and over-reliance on specific samples (eg, adolescents or adults). ${ }^{68}$ Consequently, these two issues compromise the validity of most prevalence studies whilst also limiting possible comparisons of prevalence rates across different cultural contexts. In order to mitigate some of the problems related to this aspect of IA research, this section only presents findings from studies that recruited participants using probability sampling techniques and/or included nationally representative samples.

As shown in Table 1, a total of 12 studies providing epidemiological data were published between January 2014 and February 2015 (ie, those with nationally representative samples). Interestingly, prevalence rates for IA ranged from a minimum of $1 \%$ in one study to a maximum of $18.7 \%$ in another. ${ }^{68,69}$ While all studies used cross-sectional designs to assess prevalence rates in different countries, significant heterogeneity in the assessment of IA was found alongside some arbitrariness in terms of the cutoff points adopted to ascertain prevalence rates, even when researchers had used the same instrument. It is worth mentioning that almost half of the studies included (ie, five of 12) did not assess IA with a psychometrically validated instrument. ${ }^{22,70-73}$ Additionally, with the exception of one study, ${ }^{68}$ all the remaining studies provided data on adolescent samples only, thus hampering the degree of generalizability of extant prevalence rates to other important segments of the general population such as young children and adults.

Regarding the differences in prevalence rates of IA among males and females, almost half of the studies found a higher prevalence among males, ${ }^{22,71,73,74,76}$ while only one study found higher rates in females. ${ }^{49}$ Conversely, two studies

Table I Main methodological features of studies reporting prevalence rates using random and nationally representative samples

\begin{tabular}{|c|c|c|c|c|c|c|c|c|}
\hline \multirow{2}{*}{$\begin{array}{l}\text { Supporting } \\
\text { research }\end{array}$} & \multirow[t]{2}{*}{ Prevalence } & \multirow[t]{2}{*}{$95 \% \mathrm{Cl}$} & \multirow{2}{*}{$\begin{array}{l}\text { Prevalence } \\
\text { time frame }\end{array}$} & \multirow[t]{2}{*}{ Country } & \multicolumn{2}{|l|}{ Assessment } & \multicolumn{2}{|c|}{ Sample information } \\
\hline & & & & & Instrument & Validated & Size & Characteristics $^{a}$ \\
\hline $\begin{array}{l}\text { Rücker } \\
\text { et al }{ }^{49}\end{array}$ & $11.7 \%$ & (II.4-II.9) & $\begin{array}{l}\text { Not } \\
\text { specified }\end{array}$ & Switzerland & IAT & Yes & 3,067 & $\begin{array}{l}\text { Nationally representative sample } \\
\text { of school-based adolescents }\end{array}$ \\
\hline Blinka et a ${ }^{70}$ & $1.4 \%$ & $(1.3-1.5)$ & $\begin{array}{l}\text { Not } \\
\text { specified }\end{array}$ & $\begin{array}{l}25 \text { European } \\
\text { countries }^{\mathrm{b}}\end{array}$ & EIU & No & 18,709 & $\begin{array}{l}\text { Nationally representative sample } \\
\text { of community-based adolescents }\end{array}$ \\
\hline Evren et $\mathrm{al}^{71}$ & $15.96 \%$ & $(15.7-16.1)$ & 3-month & Turkey & BAPINT-SV & No & 4,957 & $\begin{array}{l}\text { Nationally representative sample } \\
\text { of school-based adolescents }\end{array}$ \\
\hline $\begin{array}{l}\mathrm{Ha} \text { and } \\
\mathrm{Hwang}{ }^{74}\end{array}$ & $2.8 \%$ & $(2.7-2.8)$ & $\begin{array}{l}\text { Not } \\
\text { specified }\end{array}$ & South Korea & KS scale & Yes & 56,086 & $\begin{array}{l}\text { Nationally representative sample } \\
\text { of school-based adolescents }\end{array}$ \\
\hline Heo et $\mathrm{al}^{75}$ & $2.8 \%$ & $(2.7-2.8)$ & $\begin{array}{l}\text { Not } \\
\text { specified }\end{array}$ & South Korea & KS scale & Yes & 57,857 & $\begin{array}{l}\text { Nationally representative sample } \\
\text { of school-based adolescents }\end{array}$ \\
\hline Kaess et al ${ }^{72}$ & $4.2 \%$ & $(4.0-4.3)$ & $\begin{array}{l}\text { Not } \\
\text { specified }\end{array}$ & II countries ${ }^{c}$ & YDQ & No & 11,356 & $\begin{array}{l}\text { Nationally representative sample } \\
\text { of school-based adolescents }\end{array}$ \\
\hline Király et a ${ }^{22}$ & $15.5 \%$ & $(15.2-15.7)$ & $\begin{array}{l}\text { Not } \\
\text { specified }\end{array}$ & Hungary & PIUQ-6 & No & 2,073 & $\begin{array}{l}\text { Nationally representative sample } \\
\text { of school-based adolescents }\end{array}$ \\
\hline Li et $\mathrm{al}^{73}$ & $11.7 \%$ & $(11.6-11.7)$ & $\begin{array}{l}\text { Not } \\
\text { specified }\end{array}$ & $\begin{array}{l}\text { People's } \\
\text { Republic } \\
\text { of China }\end{array}$ & YDQ & No & 24,013 & $\begin{array}{l}\text { Nationally representative sample } \\
\text { of school-based adolescents }\end{array}$ \\
\hline Lin et $\mathrm{al}^{69}$ & $18.7 \%$ & $(\mid 8.5-18.8)$ & $\begin{array}{l}\text { Not } \\
\text { specified }\end{array}$ & Taiwan & CIAS & Yes & 9,510 & $\begin{array}{l}\text { Nationally representative sample } \\
\text { of school-based adolescents }\end{array}$ \\
\hline Rumpf et al ${ }^{68}$ & $1 \%$ & $(0.8-1 . I)$ & $\begin{array}{l}\text { Not } \\
\text { specified }\end{array}$ & Germany & CIUS & Yes & 8,132 & $\begin{array}{l}\text { Nationally representative } \\
\text { community-based sample }\end{array}$ \\
\hline $\begin{array}{l}\text { Tsitsika } \\
\text { et al }{ }^{76}\end{array}$ & $1.2 \%$ & $(1.0-1.3)$ & $\begin{array}{l}\text { Not } \\
\text { specified }\end{array}$ & $\begin{array}{l}7 \text { European } \\
\text { countries }^{d}\end{array}$ & IAT & Yes & 13,284 & $\begin{array}{l}\text { Random sample of school-based } \\
\text { adolescents }\end{array}$ \\
\hline $\begin{array}{l}\text { Wartberg } \\
\text { et } \mathrm{al}^{77}\end{array}$ & $3.2 \%$ & $(2.8-3.5)$ & $\begin{array}{l}\text { Not } \\
\text { specified }\end{array}$ & Germany & CIUS & Yes & $\mathrm{I}, 744$ & $\begin{array}{l}\text { Nationally representative sample } \\
\text { of school-based adolescents }\end{array}$ \\
\hline
\end{tabular}

Notes: aAll included studies adopted a cross-sectional design; ' ${ }^{b}$ Austria, Belgium, Bulgaria, Cyprus, Czech Republic, Denmark, Estonia, Finland, France, Germany, Greece, Hungary, Ireland, Italy, Lithuania, the Netherlands, Norway, Poland, Portugal, Romania, Slovenia, Spain, Sweden, Turkey, and UK. However, they reported that 4.I\% were "moderately" addicted to the Internet; 'Austria, Estonia, France, Germany, Hungary, Ireland, Israel, Italy, Romania, Slovenia, and Spain; 'Greece, Spain, Poland, Germany, Romania, the Netherlands, and Turkey.

Abbreviations: Cl, confidence interval; CIUS, Compulsive Internet Use Scale; EIU, Excessive Internet Use Scale; BAPINT-SV, The Addiction Profile Index Internet Addiction Form-Screening Version; KS scale, Internet Addiction Proneness Scale; IAT, Internet Addiction Test; YDQ, Young's Diagnostic Questionnaire; PIUQ-6, Problematic Internet Use Questionnaire; CIAS, Chen Internet Addition Scale. 
found no differences at all in terms of prevalence rates across sex. ${ }^{68,70}$ Furthermore, one study found a higher prevalence of IA among males in general and also reported that females in female-only schools were more prone to present with IA,${ }^{75}$ while another study concluded that males suffering with depression, anxiety, and peer relationship problems were more likely to exhibit IA, whilst females experiencing conduct problems or hyperactivity/inattention were more prone to exhibit IA. ${ }^{72}$

Additional information on IA prevalence rates has been provided by recent review studies. For instance, Cheng and $\mathrm{Li}^{78}$ conducted a meta-analysis in order to estimate prevalence rates of IA across several countries by searching for evidence stemming from empirical studies published between 1996 and 2012. In the study, the authors identified 164 IA prevalence rates published across 80 studies from 31 nations across seven world regions. The results showed a global prevalence of IA of around $6 \%$, with the highest rates found in the Middle East (10.9\%) and lower rates found in Northern and Western Europe (2.6\%). The authors also reported that poor quality of life was associated with higher IA prevalence rates. Although this study was, to the best of the authors' knowledge, the first to systematically address the issue of IA prevalence worldwide, several limitations were present.

Firstly, these results may not be entirely representative of the real prevalence of IA worldwide since the findings presented by the authors were restricted to reports that only used either Young's Diagnostic Questionnaire ${ }^{4}$ or the Internet Addiction Test. ${ }^{63}$ For this reason, it is possible that reliable prevalence rates reported elsewhere may have been unintentionally omitted due to strict inclusion criteria. Furthermore, to the best of the authors' knowledge, no study has ever scrutinized the psychometric properties of Young's Diagnostic Questionnaire, and this may have introduced severe biases to the prevalence rates found with this instrument. Additionally, Table 1 shows that several prevalence studies were conducted in 2014 and 2015 using other types of psychometric tools, leading to the conclusion that important and perhaps more reliable prevalence rates may have not been included in the authors' meta-analysis. Secondly, important geographic areas such as Africa were omitted from the meta-analysis by Cheng and $\mathrm{Li}^{78}$ Therefore, their findings may not be applicable to all countries. Notwithstanding the issues associated with the lack of consensual conceptualization, assessment, and shortcomings in terms of existing prevalence rates for IA, it is relatively safe to conclude that IA exists, but that the problem of IA is not as widespread as it may appear because conservative prevalence rates are systematically reported by the majority of empirical studies.

\section{Internet addiction and its associated neuronal processes}

Over the last 15 years, studies have emerged using neuroscientific techniques to study relevant brain processes, activities, and brain structures associated with both gaming and IA. ${ }^{79,80}$ Neuroimaging studies have a number of advantages over the self-reports that historically have more commonly been used in IA research. Neurobiological studies allow for an objective assessment of IA by investigating how changes in the brain may result in changes in behavior, as has been widely documented in substance-related addiction research. ${ }^{81}$

According to research in substance-related addiction, addiction develops via habituation mechanisms, whereby extended engagement in the addictive behavior leads to dopamine release in the dopaminergic pathways. ${ }^{82}$ As a consequence, the individual becomes less sensitive to natural rewards, such as food and sex, and instead seeks the addictive behavior, ${ }^{83,84}$ ultimately changing brain chemistry and leading to craving and tolerance. ${ }^{85,86}$ In periods of abstinence, the lack of dopamine release in the brain leads to withdrawal symptoms that can only be alleviated via reinstatement of the addictive behavior. ${ }^{81}$ Research also suggests that engaging in addictive behaviors may result in brain dysfunction, including in prefrontal brain regions, ie, the orbitofrontal cortex and cingulate gyrus, which are commonly associated with decision-making. ${ }^{81,87}$ Emerging research suggests that similar brain activation and changes occur for behavioral addictions, including IA.

In a systematic review of Internet and gaming addiction, Kuss and Griffiths ${ }^{80}$ identified 18 studies that used neuroscientific evidence to outline similarities between Internet and gaming addiction and more traditional substance-related addictions in brain functioning, morphometry, and associated behaviors. Since then, a number of additional research papers have been published, in what follows, the studies' results will be presented. Functional magnetic resonance imaging (fMRI) studies have shown that IA is associated with increased activation of brain areas relevant for reward experience and addiction. ${ }^{88}$ Specifically, it has been shown that Internet addicts are significantly more sensitive to rewards than controls, and they appear to be less sensitive to the negative consequences of their Internet engagement, including losses in a gambling task. This may explain prolonged engagement in excessive behaviors despite unfavor- 
able repercussions, ${ }^{88}$ and indicates excessive Internet use is associated with allostasis, a change in the reward set point, ${ }^{89}$ which leads the individual to seek the addictive behavior. Moreover, research suggests that different brain areas are activated in adolescent Internet addicts relative to healthy controls during a ball-throwing animation, ${ }^{89}$ including the thalamus, bilateral precentral area, bilateral middle frontal area, and the right temporoparietal junction, indicating that online disembodiment is reflected in the brain activity of Internet addicts in comparison with controls.

Similarly, during extended Internet use, neuroadaptation occurs, which leads to synchronization of the brain regions involved in addiction, such as the mesocorticolimbic system. ${ }^{90}$ IA has also been found to be associated with lower levels of gray matter and consequent changes in motor control, thinking, motivation, emotions, craving, and decisionmaking. ${ }^{91}$ Furthermore, research suggests that male Internet addicts have morphometric brain abnormalities, including a significantly lower orbitofrontal cortical thickness in comparison with healthy controls, ${ }^{92}$ decreased right frontal pole gray matter volume, better functional connectivity between their right frontal pole and the left ventral striatum, and a higher amplitude of low-frequency fluctuation in their bilateral ventral striatum, suggesting an impaired ability to focus on long-term goals if distracted. ${ }^{93}$

Studies using electroencephalography indicate that individuals with IA allocate their attention differently than healthy controls, suggesting impaired information processing and response inhibition in IA, ${ }^{94-97}$ leading to impulsive decisions, which may contribute to renewed engagement in the addictive behavior irrespective of potential negative consequences. These findings have now been replicated using fMRI, ${ }^{98}$ showing that when using a go/no-go paradigm, individuals diagnosed with IA are not able to inhibit their responses relative to healthy controls, and this has been linked to the lack of engaging the former's indirect frontal-basal ganglia pathway. A similar study using the Stroop paradigm with Internet addicts in comparison with healthy controls has furthermore shown that Internet addicts had stronger "Stroop effect"-related activity in the anterior and posterior cingulate cortices, ${ }^{99}$ supporting the contention that Internet addicts have impaired inhibitory control. A comparable Stroop paradigm study furthermore indicated Internet addicts use more cognitive resources for executive control and attention relative to healthy controls, as identified using fMRI, ${ }^{100}$ suggesting their cognitive flexibility is impaired.

From a neurochemical level, positron emission tomography research indicates that during gaming, dopamine is released in the striatum, and prolonged engagement in gaming reduces dopamine levels in general, ${ }^{101,102}$ leading the individual to seek the addictive behavior in order to overcome withdrawal symptoms.

The cited studies suggest that IA shares various neurobiological and neurochemical similarities with more traditional substance-related addictions, indicating that addictions should be viewed from a syndrome perspective, ${ }^{103}$ including both substance-related addictions and behavioral addictions, such as IA. The presented evidence furthermore suggests that IA is worthwhile to be considered for inclusion in the diagnostic manuals, given that our knowledge of this emerging disorder has substantially grown over the last two decades.

Nonetheless, the empirical research in this area comes with a caveat. Many studies do not clearly distinguish between IA and gaming addiction, making comparisons across studies difficult. Based on review of these studies, it is suggested that future studies: clearly distinguish between the specific Internet activities that may lead to addiction-related symptoms and problems; assess brain changes longitudinally to outline the progression of IA on a neurological level; and specifically use individuals who have been officially diagnosed with IA by mental health care professionals to clearly distinguish between high engagement and pathological Internet use. The knowledge base on IA and its neurobiological correlates has grown considerably over the last 15 years; however, more research needs to be done in order to address the context of the natural course of IA. Questions of associated brain changes and consequent changes in behavior that may require professional treatment need to be addressed longitudinally using further objective measures. Ultimately, this will prove beneficial for health care, treatment and insurance providers, and the affected individuals and their significant others.

\section{Implications for treatment, prevention, and patient-specific considerations}

Although IA is not yet an officially recognized disorder, there is no shortage of studies evidencing its detrimental effects on human health and general functioning. $1,42,45,104,105$ For this reason, this section briefly describes some of the literature focused on the treatment and prevention of IA, and also provides useful clinical information from the patients' perspective.

It is now known that all addictions, whether chemical or behavioral, share some specific characteristics that include 
salience, compulsive use or loss of control, mood modification, alleviation of distress, tolerance, withdrawal, and continuation of the behavior or substance consumption despite harmful consequences. ${ }^{106}$ Additionally, addictions may also emerge from the impaired functioning of the reward system. ${ }^{107}$

In a recent meta-analysis, Winkler et $\mathrm{al}^{24}$ examined and compared the short-term and long-term efficacy of psychological and pharmacological treatments for IA and also identified treatment moderations in a set of 16 studies that included 17 treatment conditions and 670 patients. After analyzing the selected studies, the authors reported that both psychological and pharmacological interventions were effective in treating and reducing symptoms of IA, time spent online, anxiety, and depression. Furthermore, in terms of the psychological treatments alone, of most studies reviewed, short-term efficacy was deemed to be large and robust, and also maintained over follow-up. Additionally, in terms of the studies that tested the effects of the pharmacological treatments alone, their short-term efficacy was found to be medium-to-large and robust notwithstanding the lack of follow-up data. Winkler et $\mathrm{al}^{24}$ also noted that studies reporting individual treatments, a higher number of female participants, older patients, or an American sample had larger effect sizes in terms of the outcome variables.

Regardless of the treatment approach, it has been argued by some authors that total abstinence from the Internet should not be the goal of any intervention, and that instead an abstinence from problematic online activities and regulated use of the activity should be achieved. ${ }^{106,108}$ However, more empirical evidence is needed in order to validate such claims. In a recent review conducted by Przepiorka et al ${ }^{107}$ on the existing evidence of cognitive-behavioral therapy and pharmacological treatment of IA, the authors recommended that clinicians should combine both approaches to treat this phenomenon because this strategy was found to be the most effective method for treating IA. Furthermore, it was also noted that some of the most used pharmacological interventions for IA have been extrapolated from other forms of treatments for substance-based addictions. For this reason, there appears to be evidence supporting the efficacy of some drugs in the treatment of IA, such as antidepressants (ie, escitalopram and bupropion), antipsychotics (ie, olanzapine and quetiapine), opioid receptor antagonists (ie, naltrexone combined with sertraline), and psychostimulants (ie, methylphenidate). ${ }^{24,106,107}$ It is also worth noting that many methodological shortcomings are present in studies reporting the pharmacological treatments for IA as findings from pharmacological treatments of online gaming addiction (rather than generalized IA) are often reported by these studies.

Nonetheless, in terms of psychological treatments for IA, one of the most influential models is cognitive-behavioral therapy. In several studies, this model has been used to treat IA. ${ }^{109,110}$ In this model, the first stage of treatment is focused on the behavioral aspects of the patient, so that at subsequent stages the focus of treatment is gradually shifted toward the development of positive cognitive assumptions. ${ }^{107}$ Furthermore, during therapy, Internet addicts identify false beliefs and learn how to modify them into more adaptive ones. ${ }^{107}$ Additionally, the cognitive-behavioral therapy approach advocates that patients should monitor their thoughts in order to identify affective and situational triggers associated with their addictive online behavior. ${ }^{108}$ Very often, activities not involving the use of the Internet (eg, physical activities) are also assessed to facilitate patients' engagement with those activities or to treat specific comorbidities (eg, social phobia and depression). This approach is based on the idea that physical exercise might compensate for a decrease in dopamine levels due to decreased Internet usage and also that the inclusion of sports exercise may enhance the effectiveness of the intervention. ${ }^{106} \mathrm{~A}$ more detailed account of several aspects surrounding cognitive-behavioral therapy to treat IA has been discussed in greater detail elsewhere. ${ }^{108,111-113}$

Specific variations of cognitive-behavioral therapy have also been devised to treat IA, such as CBT-IA. ${ }^{109,114}$ Young $^{115}$ proposed some strategies for the treatment of IA, including: practicing the opposite (ie, identifying patients' patterns of Internet use and then helping them disrupt their normal routine of Internet usage and adhering to new time patterns of use to break the online habits); using external stoppers (ie, real events or activities that prompt patients to disconnect from the Internet); setting goals with regard to the amount of time spent online; abstaining from a particular application that patients are unable to control; using reminder cards that serve as cues to remind the patient of the costs of IA and the benefits of breaking free from it; developing a personal inventory of activities the patient used to engage in or cannot find the time to engage in due to their excessive usage of the Internet; entering a support group to compensate for the lack of social support; and engaging in family therapy to address relational problems within the family.

Although the cognitive-behavioral therapy model for treating IA appears to be effective, there are no significant differences between this type of treatment and other psychological treatments aimed at treating IA. ${ }^{24}$ For this reason, other treatment approaches might be useful to treat this condition. 
In light of this, Liu et al ${ }^{116}$ conducted a clinical trial that aimed to treat IA using multifamily group therapy (MFGT) in a cohort of 92 participants comprising 46 adolescents with IA and their parents. Participants were allocated to either the experimental condition (ie, six sessions of MFGT intervention) or a control group (ie, waiting list). They were then administered structured questionnaires at three time points (ie, pre-intervention, post-intervention, and 3-month follow-up). After analyzing the results, the authors concluded that six sessions of MFGT was an effective strategy in reducing IA-related behaviors in adolescents. Moreover, the authors also noted that the results were maintained after a 3-month period, further concluding that Internet use was partially explained by the satisfaction of their psychological needs and improved parent-adolescent communication and closeness.

As noted by King et $\mathrm{al}^{111}$ in their systematic review on the reporting and methodological quality of IA treatment studies, almost all studies have several key limitations when analyzed with the Consolidating Standards of Reporting Trials guidelines. Furthermore, the authors found that the reviewed IA treatment studies usually present with inconsistencies in the definition and diagnosis of IA, lack randomization and blinding techniques, lack adequate controls or other comparison groups, and report insufficient information concerning recruitment dates, sample characteristics, and treatment effect sizes.

Several qualitative studies have provided insights into participants' perspectives and specific considerations regarding excessive and addictive use of the Internet. ${ }^{65,117,118} \mathrm{Li}$ et $\mathrm{al}^{65}$ conducted a qualitative study involving 27 American university students who had self-identified as intensive Internet users spending at least 25 hours a week online for non-educational or non-work-related activities, and suffered from Internet-related health and/or psychosocial problems. After collecting data from participants over several focus group sessions, the authors found various indicators that pointed out participants' own experiences of excessive and addictive Internet use. More specifically, it was found that most participants used the Internet for more than 40 hours per week for non-educational or non-work-related reasons, and suffered multiple physical and psychological problems due to intensive Internet use. ${ }^{65}$ Furthermore, participants acknowledged that it was difficult to accurately calculate the total amount of time spent on the Internet per day because of unlimited data plans on mobile devices, making the Internet constantly available, possibly causing participants to have difficulty distinguishing between the amount of the time spent on the Internet for educational or work-related purposes from that for non-school/work-related purposes. ${ }^{65}$

Qualitative findings have also demonstrated that negative emotions (eg, depressive mood, sadness, and anger), boredom, and stress associated with social-related and work-related obligations are common emotional and situational triggers for excessive Internet use.$^{65}$ Last but not least, Internet addicts may also experience a variety of adverse consequences related to intensive Internet use, such as decreased academic performance and motivation to study, ${ }^{45,119}$ increased substance use, ${ }^{49,52}$ and higher incidence of depressive symptoms, ${ }^{42,120}$ among other disorders and behavioral problems. Due to the nature of IA and its potential harmful consequences, it is important that clinicians assess excessive Internet use in their practice while also further examining the nature of Internet use and how it relates to patients' online behavior in general so that they may have a better insight into specific online behaviors and motivations underpinning excessive and harmful use.

\section{Conclusion}

The present review highlights some of the key issues surrounding research on IA from several standpoints. For this purpose, the definition and characterization of IA, its prevalence rates from robust studies (ie, those with nationally representative samples), its associated neuronal processes, and implications for treatment and prevention, along with patient-specific relevant considerations, were under scrutiny in the present review.

In regards to the definition and characterization of IA, it is clear that uncertainties regarding its status and criteria as to what constitutes IA have not yet reached consensus in the field. ${ }^{121}$ However, continuous efforts from researchers aimed at uncovering the concept's intricacies, etiology, and natural course will likely help overcome existing debates and controversies about IA. Ultimately, in order to achieve a scientific consensus, researchers will have to adopt a standard definition of IA and also put forth a solid theoretical framework that provides sufficient information on the conceptualization and operationalization of this phenomenon, both qualitatively and quantitatively, and as well as in clinically diagnostic terms.

The many different understandings and conceptualizations for what appears to be the same phenomenon (ie, IA) have generated a lot of confusion and methodological difficulties that have somewhat hindered progress in the field. Most notably, such diversity with regard to how to conceptualize and define the concept is perhaps illustrated by the heterogeneity of the prevalence rates for IA found worldwide. 
Although the IA prevalence rates reported in nationally representative samples range from a minimum of $1 \%$ to a maximum of $18.7 \%,{ }^{68,69}$ the disparity and discrepancy among rates are obvious, and therefore put into question the consistency of the assessment and theoretical framework of IA adopted by researchers.

In terms of the neuronal processes associated with IA, the extant research provides small, but convincing evidence for a link between biological brain abnormalities in patients addicted to substances and similar brain abnormalities in patients with IA. ${ }^{122}$ Furthermore, evidence from fMRI studies have identified abnormalities in frontal brain regions (especially the dorsolateral prefrontal cortex) that are believed to be responsible for cognitive control and control of inhibition. ${ }^{80,123}$ Other studies have shown that a number of regions in the cognitive control network, such as the dorsolateral prefrontal cortex, play an important role in substance addiction, suggesting that structural deficits and functional abnormalities in individuals with substance addiction might be similar to those presenting with IA (eg, similar behavior symptoms, such as tolerance, withdrawal, preoccupation, and negative repercussions). ${ }^{123}$ Despite the fact that research in this area is increasing, questions of associated brain changes and consequent changes in behavior that may require professional treatment need to be addressed longitudinally using additional objective measures including neuroscientific measures (ie, fMRI, positron emission tomography, electroencephalography), but also observational methods used in treatment and health care settings and rated by trained observers independent of treatment providers. Ultimately, this will prove beneficial for health care, treatment and insurance providers, and the affected individuals and their significant others.

Finally, the fact that behavioral addictions such as IA share some commonalities with substance-based addictions has profound implications for treating such conditions. To date, treatment for IA has been essentially provided via psychological and pharmacological therapy. Moreover, evidence for psychological treatments using cognitive-behavioral therapy seems to be flourishing, although empirical evidence for their efficacy is still sparse, warranting further studies. Additionally, in terms of pharmacological treatments, existing evidence is still extremely limited and insufficient. ${ }^{122}$ However, if it is assumed that a malfunction of the reward system underlies IA, it is reasonable to conclude that pharmacological interventions of use in treating other forms of addiction may be potentially useful as a starting point for psychopharmacological research in the area of IA. ${ }^{122}$

\section{Disclosure}

The authors report no conflicts of interest in this work.

\section{References}

1. Kuss DJ, Griffiths MD, Karila L, Billieux J. Internet addiction: a systematic review of epidemiological research for the last decade. Curr Pharm Des. 2014;20(25):4026-4052.

2. International Telecommunication Union. Measuring the Information Society Report. Geneva, Switzerland. Retrieved from: http://www.itu. int/en/ITU-D/Statistics/Documents/publications/mis2014/MIS2014_ without_Annex_4.pdf2014. Accessed April 30, 2015.

3. Young KS. Psychology of computer use: XL. Addictive use of the Internet: a case that breaks the stereotype. Psychol Rep. 1996;79(3): 899-902.

4. Young KS. Internet addiction: the emergence of a new clinical disorder. Cyberpsychol Behav. 1998;1(3):237-244.

5. Griffiths MD. Internet "addiction": an issue for clinical psychology? Clinical Psychology Forum. 1996;97:32-36.

6. Griffiths MD. Internet addiction: does it really exist? In: Gackenbach J, editor. Psychology and the Internet: Intrapersonal, Interpersonal and Transpersonal Applications. New York, NY, USA: Academic Press; 1998.

7. Griffiths MD. Technological addictions. Clinical Psychology Forum. 1995;76:14-19.

8. Griffiths MD. Internet addiction - time to be taken seriously? Addict Res Theory. 2000;8(5):413-418.

9. West R. Theories of addiction. Addiction. 2001;96(1):3-13.

10. O'Reilly M. Internet addiction: a new disorder enters the medical lexicon. Can Med Assoc J. 1996;154(12):1882.

11. Kandell JJ. Internet addiction on campus: the vulnerability of college students. Cyberpsychol Behav. 1998;1(1):11-17.

12. Greenfield DN. Psychological characteristics of compulsive Internet use: a preliminary analysis. Cyberpsychol Behav. 1999;2(5):403-412.

13. Greenfield DN. Virtual Addiction-Help for Netheads, Cyber Freaks and Those Who Love Them. Oakland, CA, USA: New Harbinger; 1999.

14. Black DW, Belsare G, Schlosser S. Clinical features, psychiatric comorbidity, and health-related quality of life in persons reporting compulsive computer use behavior. J Clin Psychiatry. 1999;60(12):839-844.

15. Block J. Issues for DSM-V: Internet addiction. Am J Psychiatry. 2008;165(3):306-307.

16. Pies R. Should DSM-V designate "Internet addiction" a mental disorder? Psychiatry (Edgmont). 2009;6(2):31-37.

17. Griffiths MD, Pontes HM. Internet addiction disorder and Internet gaming disorder are not the same. J Addict Res Ther. 2014; 5(4): 124

18. Weinstein A, Feder LC, Rosenberg KP, Dannon P. Internet addiction disorder: overview and controversies. In: Rosenberg KP, Feder LC, editors. Behavioral Addictions. San Diego, CA, USA: Academic Press; 2014.

19. Young KS, Pistner M, O’Mara J, Buchanan J. Cyber disorders: the mental health concern for the new millennium. Cyberpsychol Behav. 1999;2(5):475-479.

20. Griffiths MD. Internet addiction: Internet fuels other addictions. Student BMJ. 1999;7:428-429.

21. Griffiths MD, Szabo A. Is excessive online usage a function of medium or activity? An empirical pilot study. J Behav Addict. 2014;3(1): $74-77$.

22. Király O, Griffiths MD, Urbán R, et al. Problematic Internet use and problematic online gaming are not the same: findings from a large nationally representative adolescent sample. Cyberpsychol Behav Soc Netw. 2014;17(12):749-754.

23. Montag C, Bey K, Sha P, et al. Is it meaningful to distinguish between generalized and specific Internet addiction? Evidence from a crosscultural study from Germany, Sweden, Taiwan and China. Asia Pac Psychiatry. 2015;7(1):20-26. 
24. Winkler A, Dörsing B, Rief W, Shen Y, Glombiewski JA. Treatment of Internet addiction: a meta-analysis. Clin Psychol Rev. 2013;33(2): 317-329.

25. Brand M, Young KS, Laier C. Prefrontal control and Internet addiction: a theoretical model and review of neuropsychological and neuroimaging findings. Front Hum Neurosci. 2014;8:375.

26. Yen J-Y, Ko C-H, Yen C-F, Chen S-H, Chung W-L, Chen C-C. Psychiatric symptoms in adolescents with Internet addiction: comparison with substance use. Psychiatry Clin Neurosci. 2008;62(1):9-16.

27. Zhou Y, Lin F-C, Du Y-S, et al. Gray matter abnormalities in Internet addiction: a voxel-based morphometry study. Eur J Radiol. 2011;79(1): 92-95.

28. Tonioni F, Mazza M, Autullo G, et al. Is Internet addiction a psychopathological condition distinct from pathological gambling? Addict Behav. 2014;39(6):1052-1056.

29. Dowling NA, Quirk KL. Screening for Internet dependence: do the proposed diagnostic criteria differentiate normal from dependent Internet use? Cyberpsychol Behav. 2009;12(1):21-27.

30. Ko C-H, Hsiao S, Liu G-C, Yen J-Y, Yang M-J, Yen C-F. The characteristics of decision making, potential to take risks, and personality of college students with Internet addiction. Psychiatry Res. 2010;175(1-2):121-125.

31. American Psychiatric Association. Diagnostic and Statistical Manual of Mental Disorders (5th Edition). Arlington, VA, USA: American Psychiatric Association; 2013.

32. Marks I. Behavioural (non-chemical) addictions. Br J Addict. 1990; 85(11):1389-1394.

33. Griffiths MD. A 'components' model of addiction within a biopsychosocial framework. J Subst Use. 2005;10(4):191-197.

34. Kuss DJ, Shorter GW, van Rooij AJ, Griffiths MD, Schoenmakers TM. Assessing Internet addiction using the parsimonious Internet addiction components model - a preliminary study. Int J Ment Health Addict. 2013;12(3):351-366.

35. Kuss DJ, Shorter GW, van Rooij AJ, van de Mheen D, Griffiths MD. The Internet addiction components model and personality: establishing construct validity via a nomological network. Comput Hum Behav. 2014;39:312-321

36. Davis RA. A cognitive-behavioral model of pathological Internet use. Comput Hum Behav. 2001;17(2):187-195.

37. Caplan SE. Theory and measurement of generalized problematic Internet use: a two-step approach. Comput Hum Behav. 2010;26(5): 1089-1097.

38. Caplan SE. Problematic Internet use and psychosocial well-being: development of a theory-based cognitive-behavioral measurement instrument. Comput Hum Behav. 2002;18(5):553-575.

39. Haagsma MC, Caplan SE, Peters O, Pieterse ME. A cognitivebehavioral model of problematic online gaming in adolescents aged 12-22 years. Comput Hum Behav. 2013;29(1):202-209.

40. Floros G, Siomos K, Stogiannidou A, Giouzepas I, Garyfallos G. The relationship between personality, defense styles, Internet addiction disorder, and psychopathology in college students. Cyberpsychol Behav Soc Netw. 2014;17(10):672-676.

41. Floros G, Siomos K, Stogiannidou A, Giouzepas I, Garyfallos G. Comorbidity of psychiatric disorders with Internet addiction in a clinical sample: the effect of personality, defense style and psychopathology. Addict Behav. 2014;39(12):1839-1845.

42. Banjanin N, Banjanin N, Dimitrijevic I, Pantic I. Relationship between Internet use and depression: focus on physiological mood oscillations, social networking and online addictive behavior. Comput Hum Behav. 2015;43:308-312.

43. Odacı H, Çıkrıkçı Ö. Problematic Internet use in terms of gender, attachment styles and subjective well-being in university students. Comput Hum Behav. 2014;32:61-66.

44. Dhir A, Chen S, Nieminen M. A repeat cross-sectional analysis of the psychometric properties of the Compulsive Internet Use Scale (CIUS) with adolescents from public and private schools. Comput Educ. 2015;86:172-181
45. Reed P, Reay E. Relationship between levels of problematic Internet usage and motivation to study in university students. High Educ. 2015:1-13.

46. Kelley KJ, Gruber EM. Problematic Internet use and physical health. J Behav Addict. 2013;2(2):108-112.

47. Weinstein A, Dorani D, Elhadif R, Bukovza Y, Yarmulnik A. Internet addiction is associated with social anxiety in young adults. Ann Clin Psychiatry. 2015;27(1):2-7.

48. Sariyska R, Reuter M, Lachmann B, Montag C. Attention deficit/ hyperactivity disorder is a better predictor for problematic Internet use than depression: evidence from Germany. J Addict Res Ther. 2015;6:209.

49. Rücker J, Akre C, Berchtold A, Suris J-C. Problematic Internet use is associated with substance use in young adolescents. Acta Paediatr. February 7, 2015. [Epub ahead of print.]

50. Reed P, Osborne LA, Romano M, Truzoli R. Higher impulsivity after exposure to the Internet for individuals with high but not low levels of self-reported problematic Internet behaviours. Comput Hum Behav. 2015;49:512-516.

51. Lu X, Yeo KJ. Pathological Internet use among Malaysia university students: risk factors and the role of cognitive distortion. Comput Hum Behav. 2015;45:235-242.

52. Gámez-Guadix M, Calvete E, Orue I, Las Hayas C. Problematic Internet use and problematic alcohol use from the cognitive-behavioral model: a longitudinal study among adolescents. Addict Behav. 2015;40: 109-114.

53. Chng GS, Li D, Liau AK, Khoo A. Moderating effects of the family environment for parental mediation and pathological Internet use in youths. Cyberpsychol Behav Soc Netw. 2015;18(1):1-7.

54. Al-Gamal E, Alzayyat A, Ahmad MM. Prevalence of Internet addiction and its association with psychological distress and coping strategies among university students in Jordan. Perspect Psychiatr Care. January 30, 2015. [Epub ahead of print.]

55. Pontes HM, Griffiths MD, Patrão IM. Internet addiction and loneliness among children and adolescents in the education setting: an empirical pilot study. Aloma Rev Psicol Ciències Educ Esport. 2014;32(1):91-98

56. Li W, Garland EL, Howard MO. Family factors in Internet addiction among Chinese youth: a review of English-and Chinese-language studies. Comput Hum Behav. 2014;31:393-411.

57. Lam LT. Internet gaming addiction, problematic use of the Internet, and sleep problems: a systematic review. Curr Psychiatry Rep. 2014;16(4): $1-9$.

58. Müller KW, Beutel ME, Wölfling K. A contribution to the clinical characterization of Internet addiction in a sample of treatment seekers: validity of assessment, severity of psychopathology and type of co-morbidity. Compr Psychiatry. 2014;55(4):770-777.

59. Griffiths MD. The role of context in online gaming excess and addiction: some case study evidence. Int J Ment Health Addict. 2010;8(1): 119-125.

60. Lee JY, Park EJ, Kwon M, et al. The difference in comorbidities and behavioral aspects between Internet abuse and Internet dependence in Korean male adolescents. Psychiatry Investig. 2014;11(4): 387-393.

61. Caplan SE. Problematic Internet use in the workplace. In: Anandarajan M, Teo TSH, Simmers CA, editors. The Internet and Workplace Transformation. Armonk, NY, USA: ME Sharpe; 2006.

62. Caplan SE. Preference for online social interaction a theory of problematic Internet use and psychosocial well-being. Comm Res. 2003;30(6):625-648.

63. Young KS. Caught in the Net: How to Recognize the Signs of Internet Addiction - And a Winning Strategy for Recovering. New York, NY, USA: John Wily \& Sons Inc.; 1998.

64. Chong WH, Chye S, Huan VS, Ang RP. Generalized problematic Internet use and regulation of social emotional competence: the mediating role of maladaptive cognitions arising from academic expectation stress on adolescents. Comput Hum Behav. 2014;38(0):151-158. 
65. Li W, O’Brien JE, Snyder SM, Howard MO. Characteristics of Internet addiction/pathological Internet use in US university students: a qualitative-method investigation. PLoS One. 2015;10(2):e0117372.

66. Wartberg L, Kriston L, Kammerl R, Petersen KU, Thomasius R. Prevalence of pathological Internet use in a representative German sample of adolescents: results of a latent profile analysis. Psychopathology. 2015;48(1):25-30.

67. Weinstein A, Lejoyeux M. Internet addiction or excessive Internet use. Am J Drug Alcohol Abuse. 2010;36(5):277-283.

68. Rumpf HJ, Vermulst AA, Bischof A, et al. Occurence of Internet addiction in a general population sample: a latent class analysis. Eur Addict Res. 2014;20(4):159-166.

69. Lin I, Ko C-H, Chang Y-P, et al. The association between suicidality and Internet addiction and activities in Taiwanese adolescents. Compr Psychiatry. 2014;55(3):504-510.

70. Blinka L, Škařupová K, Ševčíková A, Wölfling K, Müller KW, Dreier M. Excessive Internet use in European adolescents: what determines differences in severity? Int J Public Health. 2015;60:249.

71. Evren C, Dalbudak E, Evren B, Demirci C. High risk of Internet addiction and its relationship with lifetime substance use, psychological and behavioral problems among 10th grade adolescents. Psychiatr Danub. 2014;26(4):330-339.

72. Kaess M, Durkee T, Brunner R, et al. Pathological Internet use among European adolescents: psychopathology and self-destructive behaviours. Eur. Child Adolesc. Psychiatry. 2014:1-10.

73. Li Y, Zhang X, Lu F, Zhang Q, Wang Y. Internet Addiction Among Elementary and Middle School Students in China: A Nationally Representative Sample Study. Cyberpsychol. Behav. Soc. Netw. 2014;17(2):111-116.

74. Ha Y-M, Hwang WJ. Gender Differences in Internet Addiction Associated with Psychological Health Indicators Among Adolescents Using a National Web-based Survey. Int. J. Ment. Health. Addict. 2014;12(5):660-669.

75. Heo J, Oh J, Subramanian SV, Kim Y, Kawachi I. Addictive Internet Use among Korean Adolescents: A National Survey. PLoS ONE. 2014;9(2):e87819.

76. Tsitsika A, Janikian M, Schoenmakers TM, et al. Internet addictive behavior in adolescence: a cross-sectional study in seven European countries. Cyberpsychol Behav Soc Netw. 2014;17(8):528-535.

77. Wartberg L, Kammerl R, Rosenkranz M, et al. The interdependence of family functioning and problematic Internet use in a representative quota sample of adolescents. Cyberpsychol Behav Soc Netw. 2014;17(1): 14-18.

78. Cheng C, Li AY. Internet addiction prevalence and quality of (real) life: a meta-analysis of 31 nations across seven world regions. Cyberpsychol Behav Soc Netw. 2014;17(12):755-760.

79. Ninaus M, Kober SE, Friedrich EVC, et al. Neurophysiological methods for monitoring brain activity in serious games and virtual environments: a review. International Journal of Technology Enhanced Learning. 2014;6(1):78-103.

80. Kuss DJ, Griffiths MD. Internet and gaming addiction: a systematic literature review of neuroimaging studies. Brain Sci. 2012;2(3): 347-374.

81. Volkow ND, Fowler JS, Wang G-J. The addicted human brain: Insights from imaging studies. J Clin Invest. 2003;111(10):1444-1451.

82. Everitt BJ, Robbins TW. Neural systems of reinforcement for drug addiction: from actions to habits to compulsion. Nat Neurosci. 2005; 8(11):1481-1489.

83. Kalivas PW, Volkow ND. The neural basis of addiction: a pathology of motivation and choice. Am J Psychiatry. 2005;162(8): 1403-1413.

84. Goldstein RZ, Volkow ND. Drug addiction and its underlying neurobiological basis: neuroimaging evidence for the involvement of the frontal cortex. Am J Psychiatry. 2002;159(10):1642-1652.

85. Brebner K, Wong TP, Liu L, et al. Nucleus accumbens long-term depression and the expression of behavioral sensitization. Science. 2005;310(5752):1340-1343.
86. Koob GF, Le Moal M. Addiction and the brain antireward system. Annu Rev Psychol. 2008;59(1):29-53.

87. Potenza MN. Should addictive disorders include non-substance-related conditions? Addiction. 2006;101:142-151.

88. Dong G, Hu Y, Lin X. Reward/punishment sensitivities among Internet addicts: Implications for their addictive behaviors. Prog Neuropsychopharmacol Biol Psychiatry. 2013;46:139-145.

89. Koob GF, Le Moal M. Drug addiction, dysregulation of reward, and allostasis. Neuropsychopharmacology. 2001;24(2):97-129.

90. Liu J, Gao XP, Osunde I, et al. Increased regional homogeneity in Internet addiction disorder: a resting state functional magnetic resonance imaging study. Chin Med J (Engl). 2010;123(14): 1904-1908.

91. Yuan K, Qin W, Wang G, et al. Microstructure abnormalities in adolescents with Internet addiction disorder. PLoS One. 2011;6(6): e20708.

92. Hong S-B, Kim J-W, Choi E-J, et al. Reduced orbitofrontal cortical thickness in male adolescents with Internet addiction. Behav Brain Funct. 2013;9(1):11.

93. Kühn S, Gallinat J. Brains online: structural and functional correlates of habitual Internet use. Addict Biol. 2014;20(2):415-422.

94. Ge L, Ge X, Xu Y, Zhang K, Zhao J, Kong X. P300 change and cognitive behavioral therapy in subjects with Internet addiction disorder: a 3-month follow-up study. Neural Regener Res. 2011; 6(26):2037.

95. Yu H, Zhao X, Li N, Wang M, Zhou P. Effect of excessive Internet use on the time-frequency characteristic of EEG. Prog Nat Sci. 2009;19(10):1383-1387.

96. Dong G, Zhou H. Is impulse-control ability impaired in people with Internet addiction disorder: electrophysiological evidence from ERP studies. Int J Psychophysiol. 2010;77(3):334-335.

97. Choi J-S, Park SM, Lee J, et al. Resting-state beta and gamma activity in Internet addiction. Int J Psychophysiol. 2013;89(3):328-333.

98. Li B, Friston KJ, Liu J, et al. Impaired frontal-basal ganglia connectivity in adolescents with Internet addiction. Sci Rep. 2014;4:5027.

99. Dong G, DeVito EE, Du X, Cui Z. Impaired inhibitory control in 'Internet addiction disorder': a functional magnetic resonance imaging study. Psychiatry Res Neuroimaging. 2012;203(2-3):153-158.

100. Dong G, Lin X, Zhou H, Lu Q. Cognitive flexibility in Internet addicts: fMRI evidence from difficult-to-easy and easy-to-difficult switching situations. Addict Behav. 2014;39(3):677-683.

101. Kim SH, Baik S-H, Park CS, Kim SJ, Choi SW, Kim SE. Reduced striatal dopamine D2 receptors in people with Internet addiction. NeuroReport. 2011;22(8):407-411.

102. Hou H, Jia S, Hu S, et al. Reduced striatal dopamine transporters in people with Internet addiction disorder. BioMed Res Int. 2012;2012: 854524.

103. Shaffer HJ, LaPlante DA, LaBrie RA, Kidman RC, Donato AN, Stanton MV. Toward a syndrome model of addiction: multiple expressions, common etiology. Harv Rev Psychiatry. 2004;12(6): 367-374.

104. Chou W-J, Liu T-L, Yang P, Yen C-F, Hu H-F. Multi-dimensional correlates of Internet addiction symptoms in adolescents with attention-deficit/hyperactivity disorder. Psychiatry Res. 2015; 225(1-2):122-128.

105. Kuss DJ, Griffiths MD, Binder JF. Internet addiction in students: prevalence and risk factors. Comput Hum Behav. 2013;29(3):959-966.

106. Cash H, Rae D, Steel H, Winkler A. Internet addiction: a brief summary of research and practice. Curr Psychiatry Rev. 2012;8(4):292.

107. Przepiorka AM, Blachnio A, Miziak B, Czuczwar SJ. Clinical approaches to treatment of Internet addiction. Pharmacol Rep. 2014;66(2):187-191.

108. Khazaal Y, Xirossavidou C, Khan R, Edel Y, Zeboun F, Zullino D. Cognitive-behavioral treatments for Internet addiction. Open Addict J. 2012;5(1):30-35.

109. Young KS. Treatment outcomes using CBT-IA with Internet-addicted patients. J Behav Addict. 2013;2(4):209-215. 
110. Young KS. Cognitive behavior therapy with Internet addicts: treatment outcomes and implications. Cyberpsychol Behav. 2007;10(5): 671-679.

111. King DL, Delfabbro PH, Griffiths MD, Gradisar M. Assessing clinical trials of Internet addiction treatment: a systematic review and CONSORT evaluation. Clin Psychol Rev. 2011;31(7):1110-1116.

112. King DL, Delfabbro PH, Griffiths MD, Gradisar M. Cognitivebehavioral approaches to outpatient treatment of Internet addiction in children and adolescents. J Clin Psychol. 2012;68(11):1185-1195.

113. King DL, Delfabbro PH, Griffiths MD. Clinical interventions for technology-based problems: excessive Internet and video game use. J Cogn Psychother. 2012;26(1):43-56.

114. Young KS. CBT-IA: the first treatment model for Internet addiction. J Cogn Psychother. 2011;25(4):304-312.

115. Young KS. Internet addiction: symptoms, evaluation and treatment. In: Vandecreek L, Knapp S, Jackson TL, editors. Innovations in Clinical Practice: A Source Book. Sarasota, FL, USA: Professional Resource Press; 1999.

116. Liu Q-X, Fang X-Y, Yan N, et al. Multi-family group therapy for adolescent Internet addiction: exploring the underlying mechanisms. Addict Behav. 2015;42:1-8.
117. Tsai C-C, Lin SSJ. Internet addiction of Adolescents in Taiwan: an interview study. CyberPsychol Behav. 2003;6(6):649-652.

118. Chou C. Internet heavy use and addiction among Taiwanese college students: an online interview study. Cyberpsychol Behav. 2001;4(5): 573-585.

119. Jia R. Computer playfulness, Internet dependency and their relationships with online activity types and student academic performance. J Behav Addict. 2012;1(2):74-77.

120. Gámez-Guadix M. Depressive symptoms and problematic Internet use among adolescents: analysis of the longitudinal relationships from the cognitive-behavioral model. Cyberpsychol Behav Soc Netw. 2014;17(11):714-719.

121. Van Rooij A, Prause N. A critical review of "Internet addiction" criteria with suggestions for the future. J Behav Addict. 2014;3(4):203-213.

122. Camardese G, Leone B, Walstra C, Janiri L, Guglielmo R. Pharmacological treatment of Internet addiction. In: Montag C, Reuter M, editors. Internet Addiction. Cham, Switzerland: Springer International Publishing; 2015.

123. Li W, Li Y, Yang W, et al. Brain structures and functional connectivity associated with individual differences in Internet tendency in healthy young adults. Neuropsychologia. 2015;70:134-144.

\section{Neuroscience and Neuroeconomics}

\section{Publish your work in this journal}

Neuroscience and Neuroeconomics is an international, peer-reviewed, open access journal focusing on the identification of brain structures and measurement of neural activity related to behavior, behavioral predictions, and decision making in health and disease. The manuscript

\section{Dovepress}

management system is completely online and includes a very quick and fair peer-review system. Visit http://www.dovepress.com/testimonials. php to read real quotes from published authors. 